\title{
Summer's Warm Surge in the North Pacific
}

\author{
Kern E. Kenyon \\ 4632 North Lane, Del Mar, USA \\ Email: kernken@aol.com
}

Received 1 July 2016; accepted 19 July 2016; published 22 July 2016

Copyright (C) 2016 by author and Scientific Research Publishing Inc.

This work is licensed under the Creative Commons Attribution International License (CC BY).

http://creativecommons.org/licenses/by/4.0/

c) (i) Open Access

\section{Abstract}

A physical mechanism is proposed for initiation of summer's warm surge, which is a large body of surface layer water, heated by the spring and summer sun, which moves north to mid- and high latitudes near the ocean's center starting from the western tropical North Pacific. As the sun approaches the equator from the south during January to March, the surface layer warms and the sea level rises due to thermal expansion, creating a downward slope to the north of the sea surface. Warm surface water will therefore begin to move north assuming that there is no counterbalancing force. At some point the colder surface water to the north, being unstable, will move south and cause the warm surface layer in the south to move farther north than the sun can urge it to do. Summer's warm surge is a transient and shallow thermal circulation that occurs every year. Measurements in the western tropics of the northward slope of the sea surface, and the northward surface flow, are needed to confirm the proposed hypothesis.

\section{Keywords}

\section{Warm Surge, North Pacific}

\section{Introduction}

There is a permanent wide warm surface current in the north pacific that diagonally connects the western tropics to the Gulf of Alaska. It flows northeast off California. This current was discovered in the 1970s [1] by studying a massive SST data set composed of millions of individual ship-injection temperatures, covering the North Pacific north of $20 \mathrm{~N}$ for over a 30-year period starting in 1947, and formatted as five degree latitude/longitude squares and one month averages. Unfortunately the so called Namias-Scripps SSTs have not been kept up to date and what there is has not been published. Several independent comparisons, using more accurate thermometers and smaller spatial samplings, have verified the signature feature revealed by the ship-injection temperatures: a large-scale (about $4000 \mathrm{~km}$ ) longitudinal maximum in sea surface temperature at mid-latitudes. Being both real and permanent the existence of this feature implies that warm water must continuously be brought to 
the region from lower latitudes in order to maintain the SST maximum. One of the main functions of this surface current, together with the return flow of colder water underneath, is to transport some of the excess heat due to absorbed solar radiation from low to high latitudes.

Sea surface temperatures of the North Pacific have also been used to deduce that a separate wide surge of warm surface water moves north out of the western tropics every summer and then crosses mid-latitudes to the west of the permanent flow [2]. Though transient the summer surge is believed to be real too. Some evidence comes from a classical world sea surface temperature atlas, H. O. 225, which is based on ship-injection temperatures [3]. Between the equator and the $80^{\circ} \mathrm{F}$ temperature contour the surface area swells to the north in spring and summer such that the temperature within the area changes very little. Such a striking characteristic has been noted and interpreted recently but otherwise it has not been mentioned in the scientific literature as far as I know. Valuable in the present context for latitudes below $20 \mathrm{~N}$, the atlas nevertheless only depicts a single realization. However, 30 years of data at mid-latitudes support the existence of the summer surge in every one of those years. Since there is more excess solar radiation absorbed at low latitudes in summer than in winter, and the permanent warm current can neither speed up, increase its depth scale beyond $100 \mathrm{~m}$ or become wider very easily, the job of the surge is to convey this excess summer heat to high latitudes.

Powerful is the recognition that the highest SSTs of the North Pacific always occur in the western tropics but that these surface temperatures are essentially no warmer in summer than in winter. This in spite of the selfevident conclusion that more solar radiation is absorbed in the upper $100 \mathrm{~m}$ in summer than in winter. A very efficient heat balance mechanism of the ocean is therefore implied to be in operation such that the rate of heat transported out of the tropics basically matches the rate of heat absorbed in the tropics, whether in summer or in winter. Evidence plus a few assumptions or approximations suggest that the extra transport mechanism in summer is northward advection, which has been called the warm summer surge for illustration.

What is discussed below is an argument designed to help explain physically how the summer warm surge comes about. Ultimately, of course, cold surface water coming south from high latitudes is largely responsible for driving the thermal convection of which the warm surge is one component. However, when cold water flows south underneath warm water going north, it is difficult or impossible to disentangle this by means of SSTs, which are the primary source of information that is readily available. If a triggering mechanism for the warm surge is to be sought, then one should probably look to the lower latitudes when the sun in warming the surface layer, as argued next.

\section{Argument}

Concentrating on the western tropics, consider that the calendar has just gone past December 21 in a particular year, and that the sun is returning toward the northern hemisphere. Immediately the surface layer north of the equator starts to heat up due the absorption of solar radiation. It is convenient to assume that there is initially no north/south motion going on in the surface layer, and what may be happening to the surface layer south of the equator will be ignored for the moment. North of the equator in the winter the surface layer contains mostly "new" water in the sense that a large volume of the surface layer, warmed in the previous spring and summer, has already exited the tropics headed north for mid- to high latitudes to be replaced at low latitudes by cooler northern water.

As the "new" surface layer water heats up, the local sea level will rise because of thermal expansion, and by the greatest amount at the equator, with the amount of sea level rise decreasing monotonically northward due to the curvature of the earth in relation to the angle of the sun's rays. A downward slope to the north of the sea level is thereby created. No matter what the magnitude of the sea level slope is, just so long as no counter-balancing force comes into play, the slope will cause surface water to flow downhill and move north. [Water is a fluid which flows in response to the least force applied; friction will not stop it.]

Observations consistent with this reasoning can be found in the H. O. 225 atlas: the area under the $80^{\circ} \mathrm{F}$ contour starts expanding north in February, in the monthly mean, and perhaps as early as January, and the $80^{\circ} \mathrm{F}$ contour itself moves north. The northward movement of temperature contours in the tropics is probably a good indicator of the northward movement of surface layer water, because the heat exchange between the ocean and the atmosphere is expected to be relatively small there compared to what happens at mid- and higher latitudes. In addition, although not considered of the highest quality, ship-drift data may be interesting to examine for the western tropics, particularly in spring and summer, for evidence of northward surface flow.

While the sun approaches the equator, the sun's rays become more direct and penetrate deeper, consequently 
thermal expansion works to augment the sea level height there. Thus the northward slope of the sea surface increases with time in the equatorial zone. Finally, the slope itself shifts north urged on by the sun's migration into the northern hemisphere.

Lack of a force balance, involving the inferred downward slope to the north of the sea surface, caused by thermal expansion resulting from absorption of solar radiation, therefore becomes a major assumption behind the present discussion. To imagine a possible northward force in the equatorial zone that could take part in a force balance with the sea surface slope is difficult, where everything going on there is very nearly east/west: winds, currents, ... For example, the Coriolis force could not do it. Measurements of the surface slope, for longitudes within the western tropical Pacific and as a function of latitude and month, would be helpful in the future for confirming (or refuting) the hypothesis. That might prove to be difficult to accomplish as well.

Interesting in this connection is that the mean position of the sun over the western tropical Pacific travels faster north than does the $80^{\circ} \mathrm{F}$ surface temperature contour (22.5 degrees of latitude in three months compared to about 10 degrees over the same time interval), but it never catches up, because the temperature contour has a head start. When the sun crosses the equator, the contour is already at almost $20 \mathrm{~N}$.

Of course the nudging of the warm surface water northward by the moving sun must come to a stop on, or shortly after, June 21, when the sun turns back south. On the other hand, observations (H. O. 225) show that the $80^{\circ} \mathrm{F}$ contour in the western tropics continues on north through August where it reaches latitude $34 \mathrm{~N}$. How is this to be understood? Evidently the main driving mechanism has already kicked in sometime before June 21. Cold surface water in the north and warm surface water in the south is an unstable situation even though separated by a large horizontal distance. When the separation distance decreases, and the associated horizontal pressure gradient increases, as it does little by little due to the warm surface water creeping northward under the influence of the sun's warmth causing the sea level to rise by thermal expansion. At some point the instability will catch on causing cold surface water to "rush" south and warm water to move north. "Rush" is a figurative term because the north/south speeds involved are expected to be in the $10-20 \mathrm{~cm} / \mathrm{sec}$ range. Anyway, that is the proposal being put forward here for an explanation of the observed SST features.

\section{Discussion}

Left out of consideration in the argument above is: what happens to the sea level right on the equator? If there exists at any time a slope to the sea level in vertical planes that intersect the equator, then there is a possibility that some surface layer water could be exchanged between hemispheres. At the two equinoxes such an event would be least likely to occur than at other times of the year, assuming thermal expansion by the sun's heating is the cause. The question has intrinsic interest, but no special bearing on the program already outlined, whatever the answer turns out to be. Also no discussion of this topic appears in the oceanographic literature to the best of my knowledge.

In the overall scheme of the ocean's heat balance, on time scales of a month to a season, significant crossequatorial flow of surface water would not be anticipated, each ocean taking care of its own business without needing help from its neighbor ocean. [Intermediate and deep flows are in a different category.] For example, the Atlantic and Pacific, both North and South, have large open water regions connecting the tropics to the subarctic and subantarctic. One exception, of course, is the northern Indian Ocean which is landlocked to the north, whereby heat flow across the equator would seem be a necessity, at least for some fraction of a year and some band of longitudes.

Since the surface temperature difference between that at the equator and that at the subarctic is directly related to the production of the warm summer surge in the North Pacific, the resulting thermal convection is expected to take place between those two latitudes and not to spill over, for example, into the South Pacific. Data may someday reveal that a similar summer warm surge occurs in the South Pacific too, only that it is 180 degrees out of phase with the one in the North Pacific. That is, it occurs in the southern summer.

There are barely enough data to make the suggestion that a permanent wide warm surface current exists in the South Pacific which is the analogue of the one in the North Pacific [4], but it is very likely to be the case and probably the two currents are independent of each other; neither one crossing the equator.

\section{Conclusion}

Given that the summer's warm surge of the North Pacific is a real and transient feature of the surface circulation 
that happens every year, how does it come about? By a two-step process, an observed signature that indicates the initiation of the warm surge is the swelling to the north of the surface area between the equator and the $80^{\circ} \mathrm{F}$ contour in the western tropics beginning in January and continuing into August. It is proposed here that between January and July the sun warms the surface layer north of the equator and causes, through thermal expansion, the sea level to rise and to slope downward to the north. Therefore, warm surface water moves north, assuming that no force is there to stop it. From July onward, when the sun is returning south, the warm surge is driven further north by means of colder surface waters of higher latitudes moving south due to an instability inherent in the large-scale north/south density structure of the surface layer. By the sun's initial influence the instability is triggered. Sea surface slope data and surface velocity observations are needed for the western tropics in order to check up on the proposal.

\section{References}

[1] Kenyon, K.E. (1981) A Shallow Northeastward Current in the North Pacific. Journal of Geophysical Research, 86, 6529-6536. http://dx.doi.org/10.1029/JC086iC07p06529

[2] Kenyon, K.E. (2016) Non-Seasonal SSTs of the Western Tropical North Pacific. Natural Science, 7, 605-612. http://dx.doi.org/10.4236/ns.2015.713060

[3] (1942) World Atlas of Sea Surface Temperatures. 2nd Edition, H. O. No. 225, U. S. Navy, Washington DC.

[4] Kenyon, K.E. (2012) Southward Flow in the Central South Pacific. Natural Science, 4, 819-824. http://dx.doi.org/10.4236/ns.2012.411109

\section{Submit or recommend next manuscript to SCIRP and we will provide best service for you:}

Accepting pre-submission inquiries through Email, Facebook, LinkedIn, Twitter, etc.

A wide selection of journals (inclusive of 9 subjects, more than 200 journals)

Providing 24-hour high-quality service

User-friendly online submission system

Fair and swift peer-review system

Efficient typesetting and proofreading procedure

Display of the result of downloads and visits, as well as the number of cited articles

Maximum dissemination of your research work

Submit your manuscript at: http://papersubmission.scirp.org/ 